\section{Commentary: This paper makes me want to golf more}

\author{
Christopher W. Seder, MD
}

The ability to generalize the results of a study to your own practice is what makes reading the literature important, interesting, and informative. It gives us data to help care for our patients, understand the intricacies of medicine, and inspires us to carry out further studies to build our field's collective knowledge base. If the information in the paper cannot be applied to one's practice, the impact of the study is diminished. Perhaps the data are still interesting, and the results something to aspire to, but in reality, they are of limited use. It's like watching Phil Mickelson play golf-it's super impressive, entertaining, and something to strive for, but I can't watch the Masters then shoot 8 under this weekend. Phil's golf game does not apply to me.

That's the feeling I got reading the article by Deng and colleagues $^{1}$ in this month's issue of JTCVS Techniques. The authors examine the impressive results of a single surgeon at a high-volume center to understand the learning curve for video-assisted thoracoscopic surgery (VATS) sleeve lobectomies. A cumulative sum (CUSUM) analysis revealed that 30 cases are required to achieve a technical foundation and 90 cases to achieve proficiency. After exclusions, the authors report 127 cases over the course of 6 years; on average, that's almost 2 VATS sleeves per month! Many surgeons, even at high-volume centers, may not perform 2 VATS sleeves per year.

The results just don't feel generalizable. So, what does one do with these data? First, let's ask a few questions. If the cases are accrued over 15 or 20 years, not over 6 years,

\footnotetext{
From the Department of Cardiovascular and Thoracic Surgery, Rush University Medical Center, Chicago, Ill.

Disclosures: The author reported no conflicts of interest.

The Journal policy requires editors and reviewers to disclose conflicts of interest and to decline handling or reviewing manuscripts for which they may have a conflict of interest. The editors and reviewers of this article have no conflicts of interest.

Received for publication July 21, 2021; revisions received July 21, 2021; accepted for publication July 30, 2021; available ahead of print Aug 20, 2021.

Address for reprints: Christopher W. Seder, MD, 1725 W Harrison St, Suite 774, Chicago, IL 60305 (E-mail: Christopher_W_Seder@rush.edu).

JTCVS Techniques 2021;9:155

2666-2507

Copyright (C) 2021 The Author(s). Published by Elsevier Inc. on behalf of The American Association for Thoracic Surgery. This is an open access article under the CC BY-NC-ND license (http://creativecommons.org/licenses/by-nc-nd/4.0/).

https://doi.org/10.1016/j.xjtc.2021.07.035
}

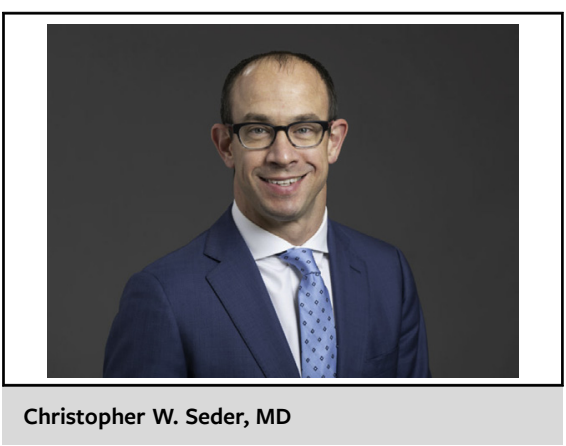

\section{CENTRAL MESSAGE \\ The results of this study may not be generalizable to most centers, but they do provide us with a baseline of what the learning curve looks like for minimally invasive sleeve lobectomies.}

does the CUSUM curve look the same? If one was able to achieve proficiency, how many VATS sleeves must to be performed annually to maintain proficiency? Would the curve look similar if the CUSUM analysis was riskadjusted for case mix? How could one shorten the learning curve and achieve similar excellent outcomes? Many thoracic surgeons would answer the last question with the following reply: simple, use robotics. The improved visualization and wristed instruments available with robotics are ideal for complex pulmonary work that requires sewing, such as sleeve lobectomies. Does the CUSUM curve look similar with robotic sleeves? Perhaps that's the next study.

The second thing this paper makes me want to do is get out and do more minimally invasive sleeves, just like watching Phil play golf makes me want to hit the course. It's good for us as a specialty to know what performance looks like at the highest level. The authors should be congratulated on providing us with their impressive results. Personally, I suspect the future of sleeve lobectomies will be with robotic technology, but this study gives us a baseline of what the learning curve looks like for minimally invasive sleeve lobectomies.

\section{Reference}

1. Deng J, Jiang L, Li S, Zhang L, Zhong Y, Xie D, et al. The learning curve of video-assisted thoracoscopic sleeve lobectomy in a high-volume pulmonary center. J Thorac Cardiovasc Surg Tech. 2021;9:143-52. 